\title{
Cardiac Tamponade after Thrombolysis for Acute Ischemic Stroke A Case with an Excellent Outcome
}

\author{
Ana Vera-Cruz ${ }^{1}$, Marta Cerol $^{1}$, Maria Margarida Pereira ${ }^{1}$, Sónia Canadas², Juliana Mortágua ${ }^{3}$, Ion Gherbovetchi ${ }^{3}$, José Pedro Andrade ${ }^{3}$ \\ ${ }^{1}$ Medicine Department, Internal Medicine Service, District Hospital of Santarém, Santarém, Portugal \\ ${ }^{2}$ Medicine Department, Internal Medicine Service, Hospital Sousa Martins, Guarda, Portugal \\ ${ }^{3}$ Emergency Department, Intermediate Care Unit, District Hospital of Santarém, Santarém, Portugal
}

\section{Doi: 10.12890/2020_001534 - European Journal of Case Reports in Internal Medicine - @ EFIM 2020}

Received: 30/01/2020

Accepted: $11 / 02 / 2020$

Published: $13 / 03 / 2020$

\begin{abstract}
How to cite this article: Vera-Cruz A, Cerol M Pereira MM, Canadas S, Mortágua, Gherbovetchi I, Andrade JP. Cardiac tamponade after thrombolysis for
\end{abstract} acute ischemic stroke - a case with an excellent outcome. EJCRIM 2020;7: doi:10.12890/2020_001534.

Conflicts of Interests: The Authors declare that there are no competing interests.

This article is licensed under a Commons Attribution Non-Commercial 4.0 License

\section{ABSTRACT}

Intravenous thrombolysis with recombinant tissue plasminogen activator (rtPA) is the established treatment for acute ischemic stroke and has been highly effective in reducing the neurological deficit. Serious adverse events are not uncommon, with hemorrhage being the major complication. We describe the case of a patient with acute ischemic stroke that also presented with vague cardiac symptoms and was treated with rtPA, which was complicated by a hemopericardium causing cardiac tamponade. Pericardiocentesis was promptly performed, which resulted in rapid resolution of the cardiogenic shock. The patient recovered consciousness within a few minutes. A search of the MEDLINE database shows that this is the first report of cardiac tamponade after rtPA thrombolysis occurring in a patient with no history of recent myocardial infarction or aortic dissection.

\section{LEARNING POINTS}

- Cardiac tamponade is a medical emergency and if not recognized and treated quickly results in cardiogenic shock and death. Hence, it is necessary to be aware that the established treatment for acute ischemic stroke can lead to cardiac tamponade.

- Cardiac tamponade after rtPA thrombolysis can occur in patients with no history of recent myocardial infarction or aortic dissection.

\section{KEYWORDS}

Acute ischemic stroke, tissue plasminogen activator, thrombolysis, hemopericardium, cardiac tamponade

\section{CASE DESCRIPTION}

A 59-year-old woman with a history of epilepsy, dyslipidemia and hypothyroidism was admitted to the emergency department with dysarthria, labial commissure deviation to the left and a right hemiparesis, $2 \mathrm{~h} 30 \mathrm{~min}$ after symptom onset. The National Institutes of Health Stroke Scale (NIHSS) was 11.

There was no history of other symptomatology prior to the neurological deficit. On examination, blood pressure was $166 / 78 \mathrm{~mm} \mathrm{Hg}$ pulse 140 beats/minute and the electrocardiogram showed atrial fibrillation. A contrast-enhanced computed tomography (CT) brain scan showed a hyperdense left middle cerebral artery. A diagnosis of acute ischemic stroke (AIS) was made and intravenous thrombolysis with recombinant tissue plasminogen activator ( $r$ PA) commenced $2 \mathrm{~h} 50$ min after symptom onset.

The patient became comatose 30 minutes after commencing thrombolysis. A second CT brain scan showed no evidence of hemorrhage. Shortly afterwards, she became hypotensive, continued in atrial fibrillation with a rapid ventricular rate and her extremities became cold. Point-of-care ultrasonography found a large amount of echodense material in the pericardium compatible with a hemopericardium causing cardiac tamponade. 
Pericardiocentesis was promptly performed, with drainage of $600 \mathrm{~mL}$ of serohematic fluid followed by the resolution of cardiogenic shock. The patient recovered consciousness within a few minutes, with a NIHSS score of 2.

\section{DISCUSSION}

Cardiac tamponade is a clinical syndrome caused by the accumulation of fluid in the pericardial space, resulting in hemodynamic compromise ${ }^{[1]}$. It is a medical emergency and if not diagnosed and treated quicklycan lead to death within minutes. Our case is the first report of a cardiac tamponade after rtPA thrombolysis occurring in a patient with no history of recent myocardial infarction or aortic dissection, based on a search of the MEDLINE database.

Cardiac tamponade after rtPA thrombolysis was reported in patients with a recent myocardial infarction and the initial guidelines of the American Stroke Association/American Heart Association and European Stroke Organisation listed a history of myocardial infarction within the previous 3 months as exclusion criteria for rtPA treatment ${ }^{[2]}$, but which now figures in the recent guidelines as a relative contraindication ${ }^{[3]}$. There is also a reported case of cardiac tamponade with a fatal outcome following inadvertent intravenous thrombolysis for aortic dissection masquerading as AIS ${ }^{[4]}$. This report shows that AIS patients may have undetected cardiac disease that potentially poses a risk for hemopericardium and life-threatening cardiac tamponade after treatment with rtPA.

In our case, the optimal outcome was due to the rapid recognition, management and treatment of cardiac tamponade. Though uncommon, cardiac tamponade must be suspected in a patient presenting with the following signs and symptoms: chest pain radiating to neck, shoulders or back; shortness of breath; jugular venous distension; weak or absent pulse; muffled heart sounds; hypotension and shock ${ }^{[1]}$. If cardiac tamponade is suspected, although a clinical diagnosis, echocardiography is recommended to confirm it. The treatment of cardiac tamponade is drainage, preferably by needle pericardiocentesis, under imaging guidance ${ }^{[1]}$. Clinicians must be aware that the established treatment for AIS can lead to cardiac tamponade.

\section{REFERENCES}

1. Jensen JK, Poulsen SH, Mølgaard H. Cardiac tamponade: a clinical challenge. E J Cardiol Pract 2017;15(17):107-113.

2. Hensen H, Spaander F, Bax M, Koppen H. Fatal hemopericardium after intravenous recombinant transplasminogeen activator ( $\mathrm{rt}$-PA) for acute ischemic stroke. Am J Emerg Med 2016;34(12):2462.e5-2462.e6.

3. DeSilva DA, Manzano JJ, Chang HM, Wong MC. Reconsidering recent myocardial infarction as a contraindication for IV stroke thrombolysis. Neurology 2011;76(21):18381840.

4. Ching S, Ting SM. When stroke is more than stroke. Am J Emerg Med 2016;34(6):1189.e1-1189.e2. 